\title{
Atuação do Psicólogo na Atenção Básica do SUS e a Psicologia Social
}

\author{
Marcela Spinardi Cintra \\ Marcia Hespanhol Bernardo \\ Pontifícia Universidade Católica de Campinas, SP, Brasil. $\quad$ Pontificia Universidade Católica de Campinas, SP, Brasil.
}

\begin{abstract}
Resumo: A visão de que o fazer dos psicólogos é clínico, pautado no modelo biomédico, se apresenta ainda muito enraizada no discurso de muitos profissionais. Parecem compreender que essa atuação é a principal, senão a única, forma de a Psicologia contribuir com os usuários do sistema de saúde e com a comunidade. Porém, alguns profissionais procuram atuar de acordo com os princípios do SUS, baseando-se em abordagens críticas da Psicologia. Eles se aproximam das comunidades e apresentam uma prática diferenciada com relação à tradicional. Assim, o objetivo desta pesquisa é conhecer práticas de alguns psicólogos inseridos na Atenção Básica, buscando identificar as bases que as fundamentam e se estão em consonância com a Psicologia Social Crítica. A pesquisa teve caráter qualitativo, usando a pesquisa participante como estratégia metodológica, juntamente com a realização de entrevistas abertas. Os participantes são três psicólogos que atuam em Unidades Básicas de Saúde de Campinas. Os resultados da pesquisa indicam que o posicionamento ético-político do profissional e uma formação voltada para a atuação no SUS são fundamentais para uma atuação crítica e contextualizada. Mostrase que o trabalho realizado para além dos muros dos Centros de Saúde tem grande relevância e é nele que as relações estabelecidas com os conceitos da Psicologia Social Crítica ficam mais evidentes. Considera-se a importância da reflexão dos psicólogos sobre suas próprias ações, além da busca por práticas inovadoras que possam ser incluídas nas políticas públicas de saúde e entende-se que os princípios da Psicologia Social Crítica fornecem subsídios para tal.
\end{abstract}

Palavras-chave: Psicologia Social Crítica, SUS, Atenção básica, Pesquisa participante. 


\title{
Psychologist's Performance in the Primary Health Care of SUS and Social Psychology
}

\begin{abstract}
The idea that what psychologists do is clinical, based on the biomedical model, is still very much rooted in their own and other professionals' discourse. They seem to understand that this action is the main, if not the only, way for psychology to contribute to the users of the health system (SUS) and to the community. However, there are professionals who seek to act according to the principles of SUS, relying on critical approaches to psychology. These professionals approach the communities and present a differentiated practice in relation to the traditional one. Therefore, the objective of this research is to know the practices of some psychologists inserted in Primary Health Care, seeking to identify the bases that underlie them and if they are in consonance with Critical Social Psychology. This research has a qualitative character, using participatory research as a method, together with the conduction of open-ended questions interviews. Three psychologists who work in Health Centers of Campinas participated in the study. In the research results, it can be observed that the professionals' ethical and political views as well as the fact of their training being shaped to perform at SUS, are fundamental to have a critical and contextualized performance. There are also considerations about the practices of these professionals, such as the work performed beyond the walls of the Health Centers and it also brings the relations established with the concepts of Critical Social Psychology. Thus, it is considered the importance of the reflection by psychologists on their own practices, as well as the search for innovative practices that can be included in public health policies.
\end{abstract}

Keywords: Critical Social Psychology, SUS, Primary Health Care, Participatory research.

\section{Actuación del Psicólogo en la Atención Básica del SUS y la Psicología Social}

Resumen: La visión de que la actuación del psicólogo es clínica, pautada en el modelo biomédico, se encuentra bastante arraigada en el discurso de muchos profesionales. Así, parecen entender que dicha actuación es la principal, o quizás la única, forma en que la psicología contribuye con los usuarios del sistema de salud y con la comunidad. Sin embargo, existen profesionales que buscan ejercer de acuerdo con los principios del SUS, apoyándose en posturas críticas de la psicología. Estos profesionales se acercan a las comunidades y presentan una práctica diferente, comparada con la tradicional. De esta forma, el objetivo de esta investigación es conocer las prácticas de algunos psicólogos que hacen parte de la Atención Básica, buscando identificar las bases que las fundamentan y si están en consonancia con la Psicología Social Crítica. Esta investigación es de carácter cualitativa, utilizando el método de la investigación participante, junto con la realización de entrevistas abiertas. En la investigación participaron tres psicólogos que ejercen en Unidades Básicas de Salud de Campinas. En los resultados, se puede observar que la posición ética y política del profesional es fundamental para tener una actuación crítica y contextualizada, así como una formación volcada hacia el ejercicio profesional en el SUS. También se muestran consideraciones sobre las prácticas de estos profesionales, como el trabajo realizado fuera de los muros de los Centros de Salud y también se exponen las relaciones establecidas con los conceptos de la Psicología Social Crítica. Se considera, por lo tanto, la importancia de la reflexión de los psicólogos sobre sus propias prácticas, y la búsqueda de prácticas innovadoras que se pueden incluir en las políticas de salud pública, y se entiende que los principios de la Psicología Social Crítica proporcionan subsidios para tal.

Palabras claves: Psicología Social Crítica, SUS, Atención básica, Investigación participante. 


\section{Apresentação}

Este artigo nasceu a partir de uma pesquisa de Mestrado Acadêmico concluída em 2016. A opção pelo tema surge de uma experiência anterior na área da Psicologia, vivenciada por uma das autoras, em uma Unidade Básica de Saúde do Sistema Único de Saúde (SUS) da cidade de Campinas, SP. A partir dessa experiência, pôde-se perceber que ainda existem muitas dificuldades no campo da Saúde Pública, principalmente quando se aborda a Saúde Mental e a atuação de psicólogos. Ainda hoje, a visão de que o fazer desse profissional é majoritariamente clínico pautado no modelo biomédico - se apresenta muito enraizada em discursos de psicólogos e demais trabalhadores. Assim, muitos parecem compreender que essa é a principal, senão a única, forma de atender aos preceitos da profissão. Porém, é importante destacar que alguns psicólogos buscam maneiras mais condizentes de atuar, valendo-se de práticas que se embasam em conceitos e princípios do SUS, se aproximando da comunidade e também apresentando um saber crítico em relação à sua própria atuação.

Considerando as dificuldades enfrentadas no campo da Saúde Pública e o fato de o número de psicólogos contratados ter mais que dobrado de 2005 até 2011, como apontam Macedo e Dimenstein (2011), sentiu-se a necessidade de explorar outras possibilidades de ação do psicólogo na Atenção Básica que vão além do atendimento clínico individual embasado na lógica privatista e liberal.

Mas, o que se define, neste artigo, como uma atuação contextualizada? Para explicar essa denominação adotada, utiliza-se o texto de Dimenstein (1998), em que a autora explica que atuar dessa forma é propiciar uma prática transformadora e reflexiva, sempre condizente com a realidade da comunidade em que se está inserido, buscando novas formas de deixar emergir o novo. Acrescenta-se aqui também que uma atuação contextualizada deve promover conscientização e empoderamento.

Dessa forma, a pergunta que guiou essa investigação foi: quais são as bases que fundamentam uma atuação mais contextualizada do psicólogo na atenção básica do SUS? Partiu-se do pressuposto de que a aqui chamada Psicologia Social Crítica, desenvolvida na América Latina, se mostra como uma das possíveis referências para embasar tal atuação, justamente por entender que há uma afinidade entre os princípios da Psicologia Social Crítica e as propostas do SUS para a
Atenção Básica. Com base nesse pressuposto, o objetivo da pesquisa apresentada aqui foi o de conhecer práticas de alguns psicólogos inseridos na Atenção Básica, buscando identificar as bases que as fundamentam e se estão em consonância com a Psicologia Social Crítica. Entende-se que essa compreensão possa ser importante para a discussão de uma formação oferecida nos cursos de Psicologia de modo a dar mais subsídios para que os futuros profissionais atuem em consonância com os preceitos do SUS.

\section{Introdução}

\section{A saúde pública e a inserção de psicólogos}

É necessário esclarecer que o que se entende por saúde "reflete a conjuntura social, econômica, política e cultural" (Scliar, 2007, p. 30). Dessa forma, cada pessoa tem uma representação sobre o que é saúde, pois depende "da época, do lugar, da classe social [...] de valores individuais, [...] de concepções científicas, religiosas, filosóficas" (Scliar, 2007, p. 30). E isso, com certeza, é um determinante para a organização de um sistema de saúde em um local e época.

No Brasil, a partir da Constituição de 1988, a saúde passa a ser um direito para todos e dever do Estado. Em 1990, o SUS é regulamentado, instituindo-se a Lei $n^{\circ}$ 8.080/1990 (Paim, 2009), que visa a promoção, a proteção e a recuperação em saúde, através de princípios como a universalidade, a gratuidade, a integralidade e a descentralização. Importante destacar que esse sistema nasceu da luta de movimentos sociais. Ele está dividido em três níveis de atenção, apresentados, aqui, da maior para a menor complexidade: o nível terciário (que envolve procedimentos de alta complexidade, tecnologia e custo); o nível secundário (que visam atender agravos à saúde que demandem profissionais especialistas ou recursos mais avançados que o nível primário) e o nível primário, lócus da pesquisa aqui apresentada, em que são realizados os procedimentos que necessitam de menos tecnologia e equipamentos, capazes de dar resolutividade à maioria dos problemas comuns à população. Também chamada de Atenção Básica, é a porta de entrada do usuário no sistema de saúde, onde acontece a referência e contrarreferência para demais serviços especializados (Brasil, 2007).

Na Atenção Básica, há cerca de uma década, começou a ser implementada a Estratégia de Saúde da 
Família (ESF), promovida pelo Ministério da Saúde. Os profissionais que defendem sua implementação, como Gomes, Cotta, Araújo, Cherchiglia e Martins (2011), acreditam que ela transformou o modelo médico individualista em um modelo de saúde coletiva. Porém, nem todos concordam com isso. Scarcelli e Junqueira (2011), por exemplo, afirmam que a estratégia apresenta um retrocesso, tendo em vista que centraliza o cuidado nos aspectos biológicos - já que a equipe da ESF é composta por médicos, enfermeiros e agentes comunitários de saúde e os demais profissionais, como é o caso do psicólogo, ficariam como apoiadores a eles, no Núcleo de Apoio à Saúde da Família (NASF).

Nesse contexto, cabe indagar como se dá sua atuação do psicólogo na Atenção Básica. Como afirmado por Campos e Guarido (2007), mesmo com um grande repertório de ações que podem ser desenvolvidas, como atividades em grupo, visitas domiciliares e oficinas, por exemplo, a maioria dos psicólogos ainda se volta para os atendimentos clínicos individuais, nos moldes dos consultórios particulares. Isso pode ser explicado pela história da inserção do psicólogo na saúde pública, como afirma Dimenstein (1998). Para a autora, por conta da crise instaurada nos anos $1970 \mathrm{e}$ 1980 e o crescente número de psicólogos se formando nas faculdades do Brasil afora, a saúde pública se mostrou como uma "nova" possibilidade para os profissionais, sem, contudo, ser acompanhado do devido preparo na sua formação. Mas também é importante destacar que a busca por um outro modelo de atuação foi um dos motivos pelos quais outros psicólogos que teciam críticas ao modelo de saúde dessa época escolheram esse campo de trabalho.

Segundo Ronzani e Rodrigues (2006), a postura individualista para tratar dos usuários vai na contramão do que seria uma atuação comprometida com a comunidade, além de também se contrapor ao conceito de saúde que norteia o SUS - que inclui os aspectos sociais nos cuidados. Com isso, pode-se afirmar que um trabalho contextualizado do psicólogo nesse nível de atenção deve se dar no sentido de empoderar indivíduos e coletividades, possibilitando que eles promovam mudanças em suas vidas. Para que isso aconteça, Amaral, Gonçalves e Serpa (2012) acreditam que o psicólogo deve se inserir, de fato, na comunidade, ou seja, no cotidiano dos moradores, compreendendo suas dinâmicas de maneira profunda e com comprometimento.
Todas essas questões esbarram na formação dos psicólogos. Muitos chegam à saúde pública sem o devido preparo para assumir esse contexto de trabalho (Dimenstein, 1998) e também há um desconhecimento de outras possibilidades de atuação (Boing, \& Crepaldi, 2010). Mas, não é só isso. Há questões como a "inexistência de local adequado [que] não permite outras práticas, falta de credibilidade das práticas psicológicas diferentes das tradicionalmente estabelecidas e ausência de preparo para atender 'demandas sociais'” (Oliveira et al, 2004, p. 82), que também devem ser levadas em conta quando se fala da atuação do psicólogo nesse espaço.

Assim, Nascimento, Manzini e Bocco (2006) afirmam que é preciso reinventar as práticas psicológicas, criando um

constante estranhamento dos paradigmas e realidades que se apresentam como prontos, autorizando-nos a inventar, no cotidiano, estratégias que não obedeçam às fórmulas prescritas, mas que, pelo contrário, possibilite o exercício de autonomia em nossas análises e gestões do dia a dia (p. 19).

Essas não precisam ser práticas mirabolantes, mas podem ser pequenos atos que, muitas vezes, não são tidos como o quefazer do psicólogo. As mesmas autoras e Dimenstein (PSI, 2009) trazem essa temática para discussão. Ações como acompanhar um jovem em sua matrícula na escola podem surtir efeito e repercutem na saúde das pessoas. É preciso, então, se libertar das amarras que prendem a atuação do psicólogo a uma única ação e dar liberdade para que ela se transforme em atividades necessárias para aquele momento. Mas como propiciar uma formação que ajude os profissionais a seguirem esse caminho sem achar que estão deixando de ser psicólogos por isso? Aqui, entendemos que a Psicologia Social Crítica desenvolvida na América Latina pode ser uma dessas bases, como expomos a seguir.

\section{Sobre a Psicologia Social Crítica}

É preciso ressaltar que existem várias denominações para falar de perspectivas psicológicas críticas desenvolvidas no contexto latino-americano, como Psicologia Crítica, Psicologia da Libertação, Psicologia Social Comunitária e até mesmo Psicologia Social Latino Americana, mas, neste artigo, optou-se por 
agrupar esses enfoques em uma denominação genérica de Psicologia Social Crítica. Entendemos que todas essas propostas têm em comum o fato de questionarem as opressões, violências e desigualdades econômicas e/ou sociais vividas pelos povos latino-americanos (Montero, 2011) e buscarem o empoderamento das comunidades para o enfrentamento dessas situações. Observa-se, assim, que elas não se configuram como áreas ou campos de atuação dentro da Psicologia, mas como um posicionamento ético-político.

Parte-se do princípio de que a Psicologia é chamada a tomar uma posição sobre os adventos da vida cotidiana, não sendo, assim, neutra. Ao assumir uma postura, cada psicólogo mostra sua posição ética e política em relação à sua prática (Martin-Baró, 2015; Patto, 1997).

Cabe ainda uma caracterização da Psicologia Social Crítica, aqui importada do texto de Nepomuceno, Ximenes, Cidade, Mendonça e Soares (2008), que a configura pela

ênfase no caráter histórico da Psicologia; por ter a realidade social como orientadora fundamental dos estudos psicológicos; combate ao objetivismo; reconhecimento do caráter ativo dos seres humanos como produtores da história; necessidade de incluir no estudo psicológico o ponto de vista dos oprimidos, compreendidos como sujeitos epistêmicos; consideração de que o conflito é parte da ação humana; reconhecimento da importância da ideologia como fenômeno psicológico; incorporação de uma concepção dinâmica e dialética dos seres humanos; fomento à autonomia e emancipação social; inclusão de estudos sobre a relação entre indivíduos e vida cotidiana, [e] a construção diária dos sentidos dados ao mundo e à vida (p. 457).

De acordo com Domingues e Franco (2014), ela foi construída

A partir de uma vertente alinhada aos movimentos latino-americanos de tradição marxista, os quais denunciaram a colonização político-científica que ocorreu por meio da aplicação direta de modelos europeus e norte-americanos em seus territórios, e buscam construir uma Psicologia Social que contribuísse para a transformação das condições de vida (p. 16).
Com isso, pode-se citar diversos autores na América Latina que escreveram sobre uma Psicologia Social Crítica, como Silvia Lane no Brasil, Ignácio Martin-Baró em El Salvador, Maritza Montero na Venezuela, Ignacio Dobles na Costa Rica, Fernando González Rey entre Cuba e Brasil e outros tantos (Conselho Regional de Psicologia, 2016).

A historicidade dos processos sociais é um aspecto destacado por esses autores. Eles acreditam que o homem é produto e produtor da sociedade em que está inserido. Outro tema que merece destaque é o das relações de poder. Martin-Baró (2014) afirma que o poder está presente em todos os aspectos da vida. É imprescindível que uma atuação transformadora, como a Psicologia Social Crítica propõe, mude também as estruturas de poder. Dessa forma, conscientização e empoderamento se tornam aspectos fundamentais para uma atuação contextualizada. Para Martin-Baró (1996), a conscientização dos povos deve ser um dos objetivos do trabalho do psicólogo, para que todos possam ter um saber crítico sobre sua realidade. Assim, o psicólogo deve dar condições para que a conscientização aconteça, para que os indivíduos e grupos possam pensar criticamente, ou seja, reverter a alienação. A conscientização também se faz necessária para que haja o empoderamento, pois só se empoderam indivíduos conscientes de sua realidade.

Com isso, podem ser desmascaradas as ideologias que justificam a exploração, a pobreza, a desigualdade e a opressão como uma providência divina, gerando o que se chama de fatalismo, que impedem que a democracia, a igualdade e o desenvolvimento pleno do ser humano avancem (Martin-Baró, 1985). E esse trabalho deve ser realizado no cotidiano.

A partir dessa breve exposição, é possível observar que existe uma convergência entre os preceitos da Psicologia Social Crítica e os princípios que regem o SUS, como a historicidade dos processos sociais, a ideia de transformação social e também do trabalho realizado com as coletividades. Mas, quais fundamentos e princípios embasam as ações dos psicólogos inseridos na Atenção Básica em Campinas? A Psicologia Social Crítica pode ser um deles?

\section{Método}

A pesquisa que deu origem a este artigo teve caráter qualitativo, se enquadrando no que Lane (1994/2006) chama de pesquisa participante, pois "acompanha durante um certo tempo o processo de 
vida social de um grupo e, dentro dele, entende[-se] as atividades e consciências individuais que se desenvolvem num contexto histórico mais amplo" (p. 76). Já na análise dos resultados obtidos, foi utilizada a hermenêutica-dialética, proposta por Minayo (2014), baseada nos escritos de Habermas (1987). Do ponto de vista metodológico, a hermenêutica busca compreender os sentidos atribuídos pelos indivíduos aos contextos em que estão inseridos. Já a dialética busca as contradições apresentadas na linguagem - que, não necessariamente é apenas verbal - para realizar uma crítica. Enquanto uma destaca a mediação, a unicidade, a outra enfatiza a diferença, o contraste. Porém, ambas partem do pressuposto de que não há um observador imparcial e se pautam na historicidade para a compreensão do sujeito/mundo (Minayo, 2014).

A pesquisa foi realizada na cidade de Campinas, no interior de São Paulo, no ano de 2016. Atualmente, de acordo com o site da Prefeitura de Campinas ${ }^{1}$, o município conta com 61 Unidades Básicas de Saúde, divididas em macrorregiões denominadas Distritos de Saúde. Todas contam com equipe multiprofissional, composta por médicos, enfermeiros, agentes comunitários de saúde e outros profissionais. Mas, só um terço deles apresenta trabalhadores de Saúde Mental - como psicólogos, psiquiatras, terapeutas ocupacionais, entre outros.

Três psicólogos participaram da pesquisa, por entender que a compreensão aprofundada do objeto de estudo é mais interessante do que a representatividade numérica. Eles trabalham em diferentes Centros de Saúde de uma das regiões mais carentes do município.

Estabeleceu-se como critério de inclusão a formação em Psicologia e que eles, necessariamente, atuassem no cargo de psicólogo de um Centro de Saúde da cidade de Campinas. O contato com os participantes se deu através da "rede de contatos" (Hammersley, \& Atkinson, 2001) das autoras. Eles foram escolhidos justamente por serem conhecidos na rede de saúde como profissionais que adotam uma postura crítica em relação à sua atuação. Todos foram indagados quanto ao interesse em colaborar com a pesquisa e, após a resposta afirmativa, foi requerida sua autorização, mediante assinatura do termo de consentimento para sua participação na pesquisa.

A fim de manter o sigilo dos participantes em relação a suas identidades, aqui são retratados com nomes fictícios. São eles: Renato, Ana Paula e Felipe. Todos têm por volta de 30 anos. Apenas Ana Paula é formada por uma universidade particular, já Renato e Felipe realizaram aprimoramento e mestrado em Saúde Coletiva em uma universidade pública. Renato afirma que, desde sua graduação, tem contato com práticas voltadas para comunidades por meio de estágios. Diz ser envolvido há tempos com o movimento estudantil e também com a militância em diferentes movimentos sociais. Ana Paula relata interesse na área da Psicologia Hospitalar desde a graduação. Já trabalhou como psicóloga em outros municípios do Estado de São Paulo e também na Assistência Social antes de mudar para a Saúde. Por fim, Felipe relata interesse por temas como Reforma Psiquiátrica e Luta Antimanicomial desde a graduação.

Para a realização da pesquisa, foi acompanhada a rotina laboral desses três psicólogos, para que se pudesse observar e participar de suas práticas cotidianas no ambiente de trabalho. O período estipulado para isso foi de dois meses junto a cada um deles, com uma frequência média de duas vezes na semana. Após cada visita, foram realizadas anotações em um diário de campo, contendo todas as informações, vivências e sentimentos da pesquisadora em relação àquele dia de trabalho. É importante salientar que a pesquisadora acompanhou cada psicólogo de forma individual, não indo a mais de um Centro de Saúde por vez. Após o período de observações, foram realizadas entrevistas abertas com cada um dos psicólogos - também de forma individual, para que não houvesse influências de outros participantes nas respostas dadas. O objetivo dessa fase da pesquisa foi esclarecer aspectos observados na primeira fase e também propiciar um momento mais reflexivo aos participantes, no qual, eles pudessem falar sobre suas vivências, ações e opiniões, sem, no entanto, se sentirem presos a uma sequência de perguntas e respostas.

\section{Resultados e discussão}

A leitura minuciosa dos diários de campo e das entrevistas propiciou que se chegasse a três categorias de análise, mas para a discussão proposta neste artigo, optou-se por apresentar duas delas. A primeira aborda as práticas realizadas por esses profissionais, dando ênfase naquelas que os próprios

${ }^{1}$ Disponível em: http://www.campinas.sp.gov.br/governo/saude/unidades/centros-de-saude/. Acessado em: 03 de junho de 2016. 
participantes afirmam como "no território", ou seja, que vão para além dos muros dos Centros de Saúde. Por fim, a última categoria discute a formação e o posicionamento ético-político dos psicólogos como sendo cruciais para uma atuação mais contextualizada nesse espaço.

\section{A atuação do psicólogo e a valorização das atividades para além dos muros dos Centros de Saúde}

Essa categoria aborda um tema muito importante para, principalmente, a Psicologia Social Crítica voltada para a ação em comunidades, que é a territorialidade. Trabalhar "no território" é uma forma muito particular que os participantes assumem ao falar sobre ações que são realizadas fora da delimitação física do Centro de Saúde, que também se configuram como uma atuação profunda e comprometida de acordo com as características e necessidades da comunidade.

Foi possível observar que os três psicólogos estavam, na maior parte do tempo, transitando pelo Centro de Saúde e também pelo território, fazendo com que os usuários tivessem liberdade para interagir com eles, mesmo que fosse apenas para cumprimentá-los. Todos eram muito receptivos em relação a essas abordagens.

Ainda sobre a territorialidade, Renato afirma que essa é uma estratégia que utiliza para acessar os usuários e que, em um caso em específico bastante complexo $^{2}$, essa inserção no território foi fundamental para que ele tivesse uma melhor compreensão sobre a vida de uma usuária. Em suas palavras

Se eu marco consulta, ela [a usuária] vai. Ela não deixa de comparecer aos atendimentos. Então, o lance de você pensar na perspectiva de conhecer o ambiente em que o sujeito vive e as relações que ele estabelece é uma outra forma de lidar com o sujeito, porque se eu não fosse visitá-la, não ia ter dimensão objetivamente de tudo que tá rolando na vida dela.

Esse é um exemplo importante para mostrar como essa inserção amplia o olhar do psicólogo para outras questões e favorece a busca por um cuidado em saúde contextualizado com a realidade que o usuário vive, mesmo que seja no âmbito da clínica. Mas, essa não é a única forma de se trabalhar "no território". Há também a possibilidade de utilizar outros espaços dentro da comunidade para se promover ações em saúde. Novamente, os três psicólogos realizam atividades em outros locais, como o Centro de Convivência (CECO), o Centro de Integração da Cidadania (CIC) e até espaços que não estavam sendo ocupados e que foram apropriados pelo Centro de Saúde para a realização de grupos. Felipe afirma que é preciso conhecer o território em que se atua para fazer diversos tipos de ofertas em saúde para os usuários. Para ele

Trabalhar no território, por exemplo, não implica só cumprir agendinha e só ficar fazendo aquilo que tá agendado ali e pronto. Se você não vai conhecer o território, não vai conseguir ofertar outras coisas que tem no território que as pessoas que você tá atendendo podem precisar, que você pode indicar. Se a gente fica psicologizando as coisas, a gente come um monte de bola no atendimento.

Ainda é possível identificar nessa fala a preocupação de Felipe em não tratar de problemas sociais como se fossem psicológicos, além da valorização de espaços e atividades que a própria comunidade já oferta para os que ali vivem.

Ana Paula também comenta as atividades realizadas em outros espaços e percebe que, quando os grupos do seu Centro de Saúde acontecem fora de seus muros, a postura dos usuários é diferente. Em suas palavras

[os usuários] preferem fazer lá... acho que lá é melhor, é um outro ambiente. Acho que fica mais acolhedor, eles gostam mais. Eu acho que despatologiza também. Então, você tira daqui [do Centro de Saúde] e vai fazer em um outro espaço. Aí, acho que dá pra pensar em outras coisas e [o usuário] não se sente num atendimento com o psicólogo "porque eu tô louco da cabeça".

\footnotetext{
${ }^{2}$ Renato relata o caso de uma usuária que sempre se apresenta no Centro de Saúde de forma muito agitada, com muita pressa, o que dificultava, inclusive, que ele entendesse sua fala. Então, quando ele se propôs a ir à casa dela, percebeu que ela acumulava potes de comida, roupas e outros objetos, mas que, por outro lado, estava sossegada. Dessa forma, ele pode compreender que "aquela desorganização toda da casa dela, de alguma maneira, dava uma continência no processo de sofrimento que atravessa".
} 
Nessas duas falas, nota-se que, para esses psicólogos, as ações concretas realizadas em espaços fora dos Centros de Saúde "despatologizam" a relação dos usuários com os profissionais de saúde, pois este deixa de estar em sua "casa" para se tornar uma "visita" no território que pertence ao outro. Essa postura reduz o caráter hierárquico estabelecido tradicionalmente entre profissionais da saúde e seus "pacientes". Além disso, também demonstra que esses psicólogos acreditam na relevância de uma atuação para além dos muros do Centro de Saúde.

Sobre essa relação assimétrica entre os profissionais e os usuários, Renato apresenta uma fala muito interessante, em que diz que

As pessoas me chamam de doutor, me colocam nesse lugar social. Mas, quando você tá dentro de um outro espaço, de uma outra natureza, você consegue estabelecer um vínculo com o sujeito que é muito mais interessante do ponto de vista da horizontalidade da relação. Você não tem que estar marcado pela assimetria do fato de você ser o cuidador, profissional contratado que tem o conhecimento, psicólogo ou médico, enfermeiro. Você tá ali dividindo com o sujeito o espaço do protagonismo, pra discussões "n" questões, que vão desde cidadania, participação social mais ampla, até ajudar em questões relacionadas à auto estima, estilo de vida, de tudo, né?

Porém, isso não significa que o psicólogo tenha que abrir mão de seu saber profissional, mas delimitar seu papel, sem que isso seja feito de forma hierarquizada, como já propunham Oddone et al. (1986) na década de 1960 com relação à saúde do trabalhador. O que se deve é somar o saber profissional ao saber do usuário sobre sua própria saúde, promovendo sua autonomia em relação ao cuidado em saúde.

O tema da territorialidade ainda remete à discussão do social como parte fundamental para se pensar no cuidado em saúde e essa reflexão sobre o social também se faz presente quando se fala na Psicologia Social Crítica. Todos os psicólogos dessa pesquisa afirmam levar em consideração essas questões. Durante a entrevista, Ana Paula é elucidativa ao afirmar que as questões sociais, com o tempo, podem gerar adoecimento

as pessoas trazem situações de violência que elas viveram. Violência intrafamiliar ou sofreu uma violência urbana, então o social atravessa o tempo todo. A história de vida da pessoa, de privação. [Essa] é uma região de classe média baixa, tem áreas de grande risco aqui. Então, é uma população que você olha e fala "teve muitos direitos negados ali pra essa pessoa", não teve acesso a muita coisa. E o tempo todo isso vai aparecendo como adoecimento.

Felipe também fala sobre isso. Para ele, muitos dilemas sociais chegam fantasiados de sofrimento psíquico e é por isso que é fundamental ter a dimensão do social no cuidado em saúde. Mas, apesar disso, é preciso esclarecer que não desconsideram o sofrimento psíquico dos indivíduos, pois as pessoas sofrem por mazelas que são produzidas socialmente.

Esses dois relatos apresentam uma clara relação com a Psicologia Social Crítica e suas premissas ético-políticas, pois considera a historicidade dos indivíduos, como já apontado por Lane (1994/2006), Martin-Baró (2015) e Freitas (2014). Como esses autores afirmam, o sujeito é produto e produtor de seu meio, sendo influenciado pelas questões sociais que atravessam a sua vida. E essa concepção pode propiciar ao psicólogo uma atuação contextualizada. Todavia, o que foi observado algumas vezes nas falas e nas atuações dos participantes da pesquisa foi um olhar para o "social", como se este fosse sinônimo de falta de acesso a recursos materiais e não envolvesse fenômenos diversos e complexos.

Porém, os psicólogos ainda realizam atividades dentro de seus Centros de Saúde, como é o caso dos atendimentos individuais. Apesar de, muitas vezes, criticados, por transportarem o modelo privatista de atuação para um local onde a realidade é outra, não se pode descartar que, para alguns casos, esse tipo de atendimento é importante e necessário (Figueiredo e Onocko-Campos, 2009) - quando não reproduz a lógica individualizante. Felipe faz uma afirmação nesse sentido. Para ele, "é lógico que o atendimento individual é muito importante e, para alguns casos, é o que tem que fazer, mas é para alguns casos. Não para tudo que a gente pega".

Renato também avalia que, em alguns momentos, esse modelo é importante, como para casos em que há queixa de abusos, agressões e outras características que considera serem complicadas de serem discutidas em grupos ou em outros espaços. Mas, ao mesmo tempo em que faz essa afirmação, relata a difi- 
culdade que sente em relação a essa prática com pessoas que têm outra "dinâmica de vida":

Eu estou cansado, cansado no sentido de careca de ver, que, em vários momentos, os agendamentos individuais que eu faço são totalmente vazios, porque, de alguma maneira, eu não consigo interagir com o sujeito no momento em que a necessidade se apresenta pra ele, em uma dimensão social do sofrimento e eu marco um horário pra ele vir falar do sofrimento dele. Mas a dinâmica da organização da vida das pessoas é totalmente diferente. Então, eu tomo um monte de cano, os usuários não vêm [...].

Sobre os atendimentos individuais que realiza, ele também afirma que não utiliza o enfoque tradicional por achar que esse modelo não dá conta de abarcar as complexidades da vida das pessoas. Ele considera que cada indivíduo tem uma família, uma história e seu lugar no mundo e que isso tudo faz com que ele possa compreender a dinâmica da vida dos usuários. Por isso, acha mais interessante trabalhar com grupos e com a própria comunidade. Ele ainda faz um desabafo em relação ao seu cotidiano, dizendo que, muitas vezes, gostaria de fazer mais em seu trabalho, mas que "não há como chegar tentando mudar todas as regras e fazer tudo do seu jeito". Para ele, existe o possível de se fazer.

Renato ainda afirma que é preciso manejo e confiança, além do tempo, para realizar atividades significativas no espaço de trabalho, pois ainda há uma pressão - tanto dos profissionais como dos próprios usuários para que o psicólogo assuma uma posição tradicional, que é o atendimento clínico individual. Ele também afirma que, por conta de seu pensamento contra hegemônico, foi desrespeitado em alguns momentos de sua vida profissional, mas mantém o que acredita:

eu estou fundamentado numa outra lógica que, para mim, faz sentido. Então, não é porque alguém vai me xingar que eu vou deixar de fazer ou deixar de acreditar naquilo que eu tenho pensado do ponto de vista da minha atuação profissional.

É interessante destacar que, mesmo que essa postura seja identificada nos três psicólogos participantes da pesquisa, foi possível perceber que eles ainda dedicam grande parte de seu tempo para ações voltadas para recuperação/tratamento em saúde. Ao ser questionado sobre isso na entrevista, Felipe afirma que se sente "preso" em realizar ações de recuperação em saúde por conta da enorme demanda por atendimentos psicológicos e que isso não pode ser ignorado. Por isso, precisa ser persistente para realizar atividades de promoção e prevenção em saúde:

Eu sinto que consigo fazer práticas de promoção porque também meto o pé pra fazer, sabe? Porque vai muito disso, porque se você deixa, [...] a demanda grita na sua cara. Se você se deixa levar pela demanda apenas, pela demanda manifesta que aparece ali pra você, você não consegue fazer promoção de saúde, por exemplo.

Nota-se que essa fala juntamente com a de Renato, destacada acima, mostram as contradições que permeiam o atendimento clínico no Centro de Saúde, pois, ao mesmo tempo em que são pressionados pela "demanda" por atendimento individual, a adesão a esse tipo de atividade é pequena.

Finaliza-se, então, essa categoria com a fala de Ana Paula que é a que mais se aproxima dos conceitos e vertentes da Psicologia Social Crítica. Ela afirma que o trabalho do psicólogo deve se dar no sentido de promover qualidade de vida e ainda complementa:

no primeiro momento [o trabalho do psicólogo] é o acolhimento, a continência, o estar ali, ver que tem alguém ali, o que a gente pode ofertar. E acho que mais amplamente, ajudando até socialmente, no acesso, na formação de grupos, na problematização com a população dessas questões sociais [e] acho que principalmente no produzir conhecimento. No ajudar a pensar como que a pessoa pode reagir a uma situação. Primeiro, ela precisa ter o básico. E acho que a gente entra aí também, porque se a gente identifica uma situação, a gente pode acionar outros parceiros também [como] $a$ Assistência [Social], a Justiça. Então, eu acho que [o trabalho do psicólogo é] tanto com a pessoa, de ajudar nesse progresso dela, das necessidades, desde a básica até a mais complexa, até a articulação também com a rede, com o CAPS [Centro de Atenção Psicossocial], CRAS [Centro de Referência de Assistência Social], Creas [Centro de Referência Especializado de Assistência Social], na garantia de direitos. 
Dessa forma, o trabalho do psicólogo deve considerar o contexto social e promover a autonomia e o empoderamento dos usuários, tanto no nível individual como no coletivo, além de trabalhar de forma intersetorial com outros serviços públicos.

\section{Sobre a formação e o posicionamento ético-político dos psicólogos}

Na introdução deste artigo foi possível observar que uma formação voltada para políticas públicas seria um importante instrumento para que o psicólogo já saísse da graduação com um olhar para essas questões e, assim, poderia ser mais fácil de realizar práticas condizentes com os preceitos do SUS, por exemplo. Nesse sentido, Renato e Felipe destacaram o quanto suas formações em Saúde Coletiva estão presentes em ações cotidianas. Ambos buscaram, por iniciativa própria, essa formação após vivências na saúde pública. Já Ana Paula não relata nenhuma formação na Saúde Coletiva, mas mais importante do que isso a ser destacado aqui é que essa profissional se mostrou muito aberta para discutir seu trabalho e aprender com os colegas. Deve-se levar em consideração o fato de ela se aproximar de Renato - por conta do NASF - o que, com certeza a tem influenciado.

Renato e Felipe também relatam que, em algum momento de suas formações, tiveram contato com a Psicologia Social e que isso os influenciou. Felipe, inclusive, cita autores das Ciências Sociais durante a entrevista. Já Renato, durante uma conversa informal, assume que tem baseado suas ações em teorias sociais. Ao comentar isso, pode-se perceber seu claro alinhamento de suas ideias com a Psicologia Social Crítica quando destaca a importância de valorizar o que a comunidade já tem e trabalhar no território. Para ele, a Psicologia Social tem um alinhamento com "as diretrizes de trabalho da Atenção Básica a partir do que o SUS preconiza".

Já Ana Paula, que sempre teve interesse na área da Psicologia Hospitalar, afirma que isso não a impediu de buscar desempenhar um trabalho condizente com os preceitos do SUS no nível primário. Ela se mostrou muito interessada em reuniões, capacitações e discussões para aprimorar sua prática, não ficando presa a modelos pré-estabelecidos.

Isso demonstra que, para além da formação acadêmica, o posicionamento ético-político também é de extrema importância quando se pensa em práticas contextualizadas. Os psicólogos apresentavam uma postura crítica e não naturalizante em relação ao seu trabalho, levando em consideração os contextos (macro e microssociais) em que estão inseridos, além da constante reflexão sobre suas ações. Ficou claro que os três têm consciência das relações de poder e possibilidades entre os grupos sociais e das contradições presentes em na sociedade, ainda que, em alguns momentos, eles mesmos apresentem algumas contradições em suas práticas e suas falas.

Uma autora que discute a importância do embasamento político por detrás das ações dos profissionais é Freitas (1998). Segundo ela, os aspectos instrumentais dependem das concepções adotadas pelo psicólogo para orientar sua prática. E isso se torna crucial quando se fala de uma atuação contra hegemônica.

Renato afirma que, desde a graduação, está envolvido com a militância (de movimentos estudantis, sociais e da luta antimanicomial) e isso com certeza influenciou e ainda influencia suas ações no Centro de Saúde. Para ele, a participação em movimentos sociais é uma dimensão de seu trabalho - e também um posicionamento ético-político. Em suas palavras

a prática profissional nunca deve estar apartada das outras dimensões da vida pessoal, social, da participação cidadã. Que nem hoje, a gente está fazendo a entrevista depois do ato da luta antimanicomial, que, de alguma maneira, na minha concepção, é uma dimensão do meu trabalho. Estar em espaços como esse, reivindicando a melhora de políticas públicas, denunciando situações em que a gente percebe que as condições mínimas pra trabalhar estão sendo agredidas [faz com que] $a$ gente perceba que precisa de mais investimentos, estar em outros espaços de formação e debate.

A visão de mundo também aparece nas ações cotidianas dos participantes da pesquisa, como foi possível perceber durante um grupo liderado por Felipe. Muitos estigmas em relação à vida dos usuários foram aparecendo durante as conversas do grupo e, por ter uma crítica em relação a essas afirmações preconceituosas, Felipe as problematizou. Isso demonstra o quanto o posicionamento ético-político do psicólogo aparece no dia a dia e que, se tais estigmas não forem questionados e debatidos, não serão superados. Nesse sentido, o movimento da luta antimanicomial se coloca, tanto Renato como Felipe, 
como uma forma de garantir os direitos dos usuários de saúde mental.

A partir das experiências aqui relatadas, pode-se estabelecer a diferença entre prática e práxis. Bottomore (1997) explica a diferença entre essas duas palavras que constantemente são tidas como sinônimos. Para o autor, a práxis é uma ação/atividade em que o homem cria e transforma a si mesmo e a sua história. Assim, necessariamente, está atrelada a uma reflexão sobre essa ação/atividade. Já a prática é uma ação sem reflexões e questionamentos, em que há reprodução de ações. Aqui, nota-se que as atividades do cotidiano dos psicólogos da Atenção Básica de Campinas são atendimentos individuais, atividades "no território", grupos de diversos caráteres e reuniões, por exemplo.

Mas, então, o que muda de uma prática para uma práxis? Nesta pesquisa, parece ser o posicionamento ético-político que embasa a atuação dos participantes e não teorias específicas. Não se pode esquecer que não existe ação humana que não seja ideológica, como bem afirmam Martin-Baró (2015) e Patto (1997). Assim, a atuação do psicólogo também o é. Renato, por exemplo, afirma que se embasa nas teorias sociais, enquanto que Felipe diz ter estudado Lacan, autores da Psicologia Social e também da Saúde Coletiva. Apesar de Ana Paula apresentar um percurso acadêmico diferente dos outros dois psicólogos, é ela quem afirma que o olhar voltado para o SUS deve começar logo na graduação:

[Eu] não me lembro em ter tido muita ênfase em políticas públicas, eu fui aprender isso na prática, estudando para concurso, porque dai pede. Aí que eu fui conhecer mais essa parte de políticas públicas. Então, eu acho que isso já tem que começar na graduação. A gente tem que ter uma graduação que amplie os olhares para as diferentes possibilidades da Psicologia [...]. Tem que começar na base porque daí a gente já vai aprendendo mesmo as diferentes formas de atuar, porque senão fica muito difícil. A gente vai apanhando e é meio na marra que você vai descobrindo. Essa coisa do setting, do consultório, imagina né? Aqui, eu atendo cada dia em um consultório, na casa, em conjunto, atende no corredor, então é muito diferente.

Essa sua fala mostra um aspecto muito importante defendido neste artigo. Uma formação com embasamento nos princípios da Psicologia Social Crí- tica poderia ser interessante para apresentar ao aluno que a Psicologia vai muito além do que o consultório privado. Dessa forma, ao oferecer espaços "críticos" na graduação, os estudantes poderiam voltar seus olhares para questões sociais, gerando, inclusive, maior interesse em atuar em políticas públicas, seja no campo da saúde ou em outros. Aqui, os psicólogos seguiram suas formações por caminhos diversos, mas, com certeza, a ênfase crítica na graduação poderia ser um facilitador para que se encontrassem muito mais Renatos, Felipes e Anas Paulas atuando em serviços públicos de saúde, assistência e tantos outros onde uma atuação contextualizada é imprescindível.

\section{Considerações finais}

A pesquisa aqui apresentada permitiu afirmar que os psicólogos participantes não limitam suas ações a atendimentos clínicos tradicionais, realizando muitas outras atividades, como grupos dos mais variados tipos, reuniões com escolas e entre profissionais e visitas domiciliares para citar alguns exemplos. Também pode-se observar o quanto as atividades realizadas fora do espaço dos Centros de Saúde são importantes quando se pensa em uma atuação contextualizada. A aqui chamada de atuação "no território" se mostra imprescindível para esse tipo de ação comprometida.

Com isso, destaca-se a importância de que a atuação do psicólogo nesse local não se limite a uma prática curativa e individualizante, mas que abranja ações que promovam autonomia, conscientização e empoderamento, visando a transformação social da comunidade. A horizontalidade das relações também é um aspecto a ser considerado, pois permite um olhar entre "iguais" para uma atuação contextualizada. Não se pode esquecer das lutas por melhores condições de trabalho e pela defesa de direitos, como foi visto em atividades realizadas no dia de luta antimanicomial, como importantes momentos de militância, em que o posicionamento ético-político dos psicólogos ficou muito evidente.

Foi possível concluir que mais importante do que a atividade em si é o posicionamento ético-político por detrás dela. Mesmo sabendo da dificuldade de práticas inovadoras, elas são importantes para um cuidado em saúde que busca superar o modelo clínico tradicional. A reflexão sobre novos fazeres que aflorem o lado criativo que Dimenstein (PSI, 2009) tanto fala em seu texto permite que os psicólogos saiam de lugares pré-estabelecidos rumo a uma prática comprometida socialmente. 
Este artigo busca deixar claro que não apenas uma teoria pode propiciar essa atuação contextualizada, mas que um posicionamento ético-político crítico sobre a realidade e sobre a saúde impacta positivamente na maneira de atuar. Dessa forma, defende-se que uma formação crítica, com perspectivas como as da Psicologia Social Crítica pode favorecer a uma maior reflexão para os alunos e profissionais da saúde.
Entende-se as limitações deste artigo, especialmente, no que diz respeito à impossibilidade de fazer comparações com outros profissionais que não possuem as características apresentadas pelos participantes escolhidos. Todavia, acredita-se que a contribuição deste trabalho tenha sido a de evidenciar que, apesar do cenário desfavorável para as políticas públicas, é possível, e cada vez mais necessário, desenvolver uma atuação crítica.

\section{Referências}

Amaral, M. S., Gonçalves, C. H., \& Serpa, M. G. (2012). Psicologia Comunitária e a Saúde Pública: relato de experiência da prática Psi em uma Unidade de Saúde da Família. Psicologia: Ciência e Profissão, 32(2), 484-495. https://doi.org/10.1590/S1414-98932012000200015

Böing, E., \& Crepaldi, M. A. (2010). O psicólogo na atenção básica: uma incursão pelas políticas públicas de saúde brasileiras. Psicologia: Ciência e Profissão, 30(3), 634-649. https://doi.org/10.1590/S1414-98932010000300014

Bottomore, T. (1997). Dicionário do pensamento marxista. Rio de Janeiro, RJ: Zahar.

Brasil. (2007). Conselho Nacional de Secretários de Saúde. Atenção Primária e Promoção da Saúde. Brasília, DF: o autor.

Campos, F. C. B., \& Guarido, E. L. (2007). O psicólogo no SUS: suas práticas e as necessidades de quem o procura. In: M. J. P. Spink, A psicologia em diálogo com o SUS: prática profissional e produção acadêmica (pp. 81-103). São Paulo, SP: Casa do Psicólogo.

Conselho Regional de Psicologia SP - CRPSP. (2016, 11 de abril). Edgar Barrero: "Precisamos de uma psicologia latino-americana transformadora”. Jornal PSI, (186). Recuperado de http://www.crpsp.org/site/fique-de-olho-interna.php?noticia=1187\&titulo=Edgar\%20Barrero:\%20\%93Precisamos\%20de\%20uma\%20psicologia\%20latino-americana\%20transformadora\%94

Dimenstein, M. D. B. (1998). O psicólogo nas Unidades Básicas de Saúde: desafios para a formação e atuação de profissionais. Estudos de Psicologia (Natal), 3(1), 53-81.

Domingues, A. R. \& Franco, E. M. (2014). Reflexões teóricas sobre sujeitos coletivos e experiências comunitárias. In: C. Stella (Org.), Psicologia comunitária: contribuições teóricas, encontros e experiências (pp. 15-44). Petrópolis, RJ: Vozes.

Figueiredo, M. D. \& Onocko-Campos, R. (2009). Saúde Mental na atenção básica à saúde em Campinas, SP: uma rede ou um emaranhado? Ciência \&Saúde Coletiva, 14(1): 129-138.https://doi.org/10.1590/S1413-81232009000100018

Freitas, M. F. Q. (1998). Inserção na comunidade e análise de necessidades: reflexões sobre a prática do psicólogo. Psicologia: Reflexão e Crítica, 11(1), 175-189. https://doi.org/10.1590/S0102-79721998000100011

Freitas, M. F. Q. (2014). Psicologia Social Comunitária como politização da vida cotidiana: desafios à prática em comunidade. In: C. Stella, (Org.), Psicologia Comunitária: contribuições teóricas, encontros e experiências (pp. 65-85). Petrópolis, RJ: Vozes.

Gomes, K. O., Cotta, R. M. M., Araújo, R. M. A., Cherchiglia, M. L., \& Martins, T. C. P. (2011). Atenção Primária à Saúde: a "menina dos olhos" do SUS: sobre as representações sociais dos protagonistas do Sistema Único de Saúde. Ciências \& Saúde Coletiva, 16(Supl.1), 881-892. https://doi.org/10.1590/S1413-81232011000700020

Habermas, J. (1987). Dialética e hermenêutica. Porto Alegre: L\&PM.

Hammersley, M., \& Atkinson, P. (2001). Etnografía: métodos de investigación. Barcelona: Paidós.

Lane, S. T. M. (1994/2006). Avanços da psicologia social na América Latina. In: S. T. M. Lane, \& B. B. Sawaia (Orgs.), Novas veredas da psicologia social (pp. 67-81). São Paulo, SP: Brasiliense.

Macedo, J. P., \& Dimenstein, M. (2011). Expansão e interiorização da Psicologia: reorganização dos saberes e poderes na atualidade. Psicologia: Ciência e Profissão, 31(2), 296-313. https://doi.org/10.1590/S1414-98932011000200008 
Martin-Baró, I. (2015). Acción e ideología: psicología social desde centroamérica (17a ed.). San Salvador: UCA Editores.

Martin-Baró, I. (1985). La desideologización como aporte de la Psicología Social al desarrollo de la democracia en Latinoamérica. Boletín de la AVEPSO, 11(3), 3-9. Recuperado de http:/ /www.uca.edu.sv/coleccion-digital-IMB/ wp-content/uploads/2015/11/1985-La-desideologizacion-como-aporte-de-la-psicologia-social-al-desarrollo-AVEPSO1985-8-3-3_9.pdf

Martín-Baró, I. (1996). O papel do psicólogo. Estudos de Psicologia (Natal), 2(1), 7-27. https://doi.org/10.1590/S1413-294X1997000100002

Martin-Baró, I. (2014). Processos psíquicos e poder. Revista Psicologia Política, 14(31), 591-608. Recuperado de http://pepsic.bvsalud.org/scielo.php?script=sci_arttext\&pid=S1519-549X2014000300011

Minayo, M. C. S. (2014). O desafio do conhecimento: pesquisa qualitativa em saúde (14a ed.). São Paulo, SP: Hucitec.

Montero, M. (2011). Ser, fazer e parecer: crítica e libertação na América Latina. In: R. S. L. Guzzo, \& F. Lacerda Junior (2011). Psicologia social para a América Latina: o resgate da psicologia da libertação (2a ed., pp. 87-100). Campinas, SP: Alínea.

Nascimento, M. L., Manzini, J. M., Bocco, F. (2006). Reinventando as práticas Psi. Psicologia \& Sociedade, 18(1), 15-20. http://dx.doi.org/10.1590/S0102-71822006000100003

Nepomuceno, L. B., Ximenes, V. M., Cidade, E. C., Mendonça, F. W. O., \& Soares, C. A. (2008). Por uma psicologia comunitária como práxis de libertação. Psico, 39(4), 456-464. Recuperado de http://revistaseletronicas.pucrs.br/ ojs/index.php/revistapsico/article/view/3532/3836

Oddone, I., Marri, G., Gloria, S., Briante, G., Chiattella, M., \& Re, A. (1986). Ambiente do trabalho: a luta dos trabalhadores pela saúde. São Paulo, SP: Hucitec.

Oliveira, I. F., Dantas, C. M. B., Costa, A. L. F., Silva, F. L., Alverga, A. R., Carvalho, D. B. et al. (2004). O psicólogo nas unidades básicas de saúde: formação acadêmica e prática profissional. Interações, 9(17), 71-89. Recuperado de http://pepsic.bvsalud.org/scielo.php?script=sci_arttext\&pid=S1413-29072004000100005

Patto, M. H. S. (1997). Para uma Crítica da Razão Psicométrica. Psicologia USP, 8(1), 47-62. https://doi.org/10.1590/S0103-65641997000100004

Paim, J. S. (2009). Uma análise sobre o processo da Reforma Sanitária brasileira. Saúde em Debate, 33(81), 27-37. Recuperado de http://www.nesc.ufpr.br/processoseletivo2015/politicas/PAIM,\%20Jairnilson\%20-\%20Uma\%20 an\%C3\%Allise\%20sobre\%20o\%20processo\%20da\%20Reforma\%20Sanit\%C3\%Alria\%20brasileira.pdf

PSI. (2009). Conversando com um psicólogo. Magda Dimenstein sem medo de pensar. (). Psi Jornal de Psicologia, (161). Recuperado de http://www.crpsp.org.br/portal/comunicacao/jornal_crp/161/frames/fr_conversando_ psicologo.aspx

Ronzani, T. M., \& Rodrigues, M. C. (2006). O psicólogo na atenção primária à saúde: contribuições, desafios e redirecionamentos. Psicologia: Ciência e Profissão, 26(1), 132-143. https://doi.org/10.1590/S1414-98932006000100012

Scarcelli, I. R., \& Junqueira, V. (2011). O SUS como desafio para a formação em Psicologia. Psicologia: Ciência e Profissão, 31(2), 340-357. https://doi.org/10.1590/S1414-98932011000200011

Scliar, M. (2007). História do conceito de saúde. Physis: Revista de Saúde Coletiva, 17(1): 29-41. https://doi.org/10.1590/S0103-73312007000100003

\section{Marcela Spinardi Cintra}

Pontifícia Universidade Católica de Campinas

E-mail: marcelaspinardi@gmail.com

\section{Marcia Hespanhol Bernardo}

Pontifícia Universidade Católica de Campinas

E-mail: marciahespanhol@hotmail.com 
Psicologia: Ciência e Profissão Out/Dez. 2017 v. 37 n4, 883-896.

Endereço para envio de correspondência:

Marcela Spinardi Cintra

Endereço: Alameda Colombina, 704 - Condomínio Terras de São José

Itu/SP

Recebido 14/03/2017

Aprovado 17/10/2017

Received $03 / 14 / 2017$

Approved 10/17/2017

Recibido 14/03/2017

Aceptado 17/10/2017

Como citar: Cintra, M. S., \& Bernardo, M. H. (2017). Atuação do Psicólogo na Atenção Básica do SUS e a Psicologia social. Psicologia: Ciência e Profissão, 37(4), 883-896. https://doi.org/10.1590/1982-3703000832017

How to cite: Cintra, M. S., \& Bernardo, M. H. (2017). Psychologist's performance in the Primary Health Care of SUS and social Psychology. Psicologia: Ciência e Profissão, 37(4), 883-896. https://doi.org/10.1590/1982-3703000832017

Cómo citar: Cintra, M. S., \& Bernardo, M. H. ( (2017). Actuación del Psicólogo en la Atención Básica del SUS y la Psicología social. Psicologia: Ciência e Profissão, 37(4), 883-896. https://doi.org/10.1590/1982-3703000832017 